\title{
DEVELOPMENTS AND TRENDS IN THE METHODOLOGY OF PSYCHO-SOCIAL RESEARCH Romeo Zeno CRETU*
}

\section{Abstract:}

This paper presents some paradigmatic shifts that emerged in the last years in the field of psychosocial research. There are reviewed separately those upgrades that took place in quantitative and qualitative methodology. For both methodological fields there are presented the dominant theoretical conception together with their most relevant methods and instruments used for data collecting and processing.

Key words: trends of research, quantitative and qualitative methodology.

\section{Developments and trends in quantitative methodology}

The investigation in the field of psycho-social sciences, especially in the area of psychology, constantly evolved in the direction of instruments, methods and employed procedures' objectification.

As Capaldi and Proctor (2008) stated, the main focus upon the experimental method and the control of environmental variables, represented the major factor that allowed psychology to become a scientific discipline. The main purpose of psychology, like any other science, is to develop a valid theory to guide the practice of specialty. For the majority of specialists a scientific theory represents a set of deducted regularities that through interaction serve description, explanation and prediction of empirical phenomena.

The validation and reliability of the offered explanations are the key elements in any scientific approach. During the last years, researchers succeeded to provide more and more complex explanations regarding the processes and structure of human behavior and also improved predictive possibilities. For these results to be achievable a revision and sometimes even a complete change of the old models and paradigms of research was necessary.

The specialized literature from journals, the programs of international conferences and of doctoral and post-doctoral schools indicate today the following trends in research methodology that we present in next sections.

* Romeo Zeno CRETU is a university lecturer PhD at the Faculty of Psychology and Sciences of Education, University of Bucharest. E-mail: zenocretu@yahoo.com 


\section{Alternative paradigms: nomothetic vs. idiographic}

One of the most profound mutations that took place in the field of psychology is represented by the shift from the nomothetic approaches to the idiographic ones. Initially, this mutation occurred within the personality psychology but was soon reflected in other psychological branches like developmental psychology, educational psychology, psychotherapy, etc, and in domains such as behavioral genetics and epigenetics. For this reason we shall analyze the movement of this paradigm into the field of personality.

The nomothetic paradigm governed research for many decades. Its particularity consists in conceptualizing the dispositional traits of personality as fundamental units of analysis. These were considered to be the sources that control nonrandom variations within the whole behavioral variations registered for each person. Enclosed in this paradigm only the structural aspect was approached, being left aside the procedural one. In this case the level of focalization of analyses is macro. The nomothetic perspectives could not offer explanations upon the formation process of the factors, these being analyzed as given structures.

In the case of traits, the operational view and the measurement methodology became crystallized relatively rapid and unitary in the so called Classic-Dispositional Theory, respectively in the Classic Theory of Tests.

The renowned nomothetic approaches applied to personality (e.g. Five Factors Models) function on the basis of aggregation of data collected at individual level. Therefore, the assumption is that traits extracted through factorial analyses applied to inter-individual level, can explain the intra-personal structuring because it provides indirectly information concerning the mental organizing and functioning peculiar to a person Epstein and O'Brien 1985; Johnson,1997; McCrae, 2005; McCrae \& Costa, 1999, Mervielde, 1994; Ten Berge \& De Raad, 1999).

The Big Five models state that latent inter-personal variables, crossculturally replicated, are structures characteristic to each individual: "the raw universal matter that defines the potential and the direction of the individual" (McCrae \& Costa, 1996, p.68). However, these assumptions were not sustained by robust empirical evidence.

Researchers gradually acknowledged the fact that personality's operationalization in trait-factors presents incapacity in handling properly the dynamic interaction between all hierarchic levels of organization, and also between these levels and the environment. Practically, this paradigm eluded 3 major aspects:

- The processes that lead to the formation of personality structure;

- The multilevel organization of a stable answer and the interaction of these levels; 
- The role of situational variables in the formation and functioning of the personality structure.

The idiographic paradigm emerged when conceptual limits and unsatisfactory research results from the nomothetic perspective were pointed out (Mischel and Shoda, 1995). For this paradigm, the unit of analysis became the behavior and/or the dispositional construct, the focus being directed upon identifying the underlying processes that maintain the predictable behavioral patterns. The level of analysis for this approach is micro (see figure 1).

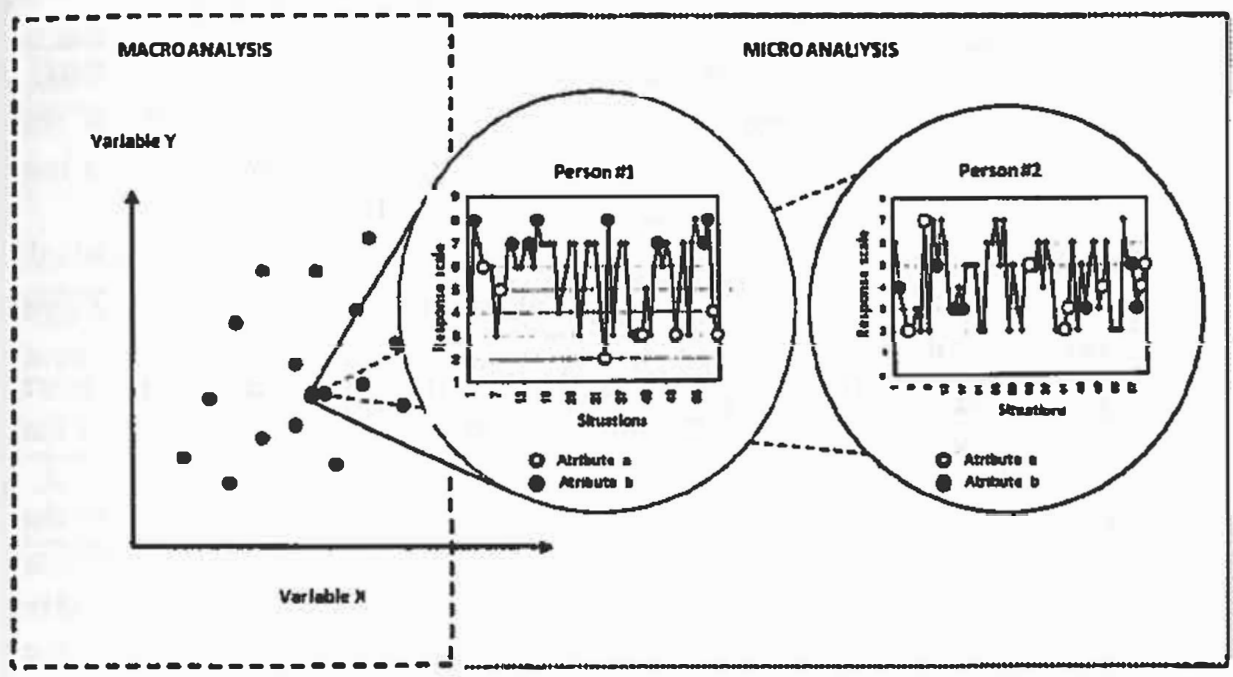

Figure 1. Two distinct levels of analysis in psycho-social research (adapted from: Shoda and Lee Tiernan, 2002)

By contrast, the dispositional constructs were defined from various conceptual perspectives, in several successive stages and the methodologies employed from one research to another were less unitary.

Nowadays, there are accumulated a multitude of formal and empirical arguments in order to sustain the fact that the idiographic paradigm is more adequate in the scientific research of personality, regardless of the applied branch of it. However, from the quantitative point of view, the structural researches of personality still pervade in the scientific offer that the reader has access to, such as specialized journals and conferences that are found in the whole world. Next, we present some of the essential nomothetic limits signaled by those who configured the idiographic trend.

The applied aggregation at the level of individuals is a necessary condition in replicating factors, but it disintegrates the personality as individual entity. 
Borsboom et al. (2006), taking into consideration the assumptions of the Big Five adherents, proved that "the between-subject models do not imply, test or support causal explaining at individual level"(p.214). The lack of isomorphism between the inter-individual and intra-individual levels cancels the assumption according to which two persons having the same level of manifestation concerning certain characteristics will also have the same intrasubjective dynamic.

Schimz (2000) analyzed several errors that arise when data aggregation is used by researcher, formulating three theorems:

- Tl: the medium aggregated distributions do not allow the extraction of conclusions about the individual distributions. Blastland and Dilnot (2009) plastically presented this situation:" we are aware of the rainbow colours' vibration and we know as well what we would lose if we combined them to obtain a mixed white band on the sky".

- T2: the correlations of the aggregated data at the level of individuals do not allow the derivation of conclusions regarding individual correlations;

- T3: crossed analyses of longitudinal data for two observational points do not allow extracting conclusions concerning crossed relations that would characterize isolated individuals..

- Molenaar (2004), provided others formal demonstrations, indicating that the Ergodic theorem implies two absolutely necessary conditions for the inter-individual analysis (macro) to become validly equivalent with the intra-individual one (micro). The psychological processes (inter and intra individual) must be stationary. This means that the measured processes should display constant statistical characteristics. The statistical parameters of data (e.g. means, correlations, factorial loadings etc.) should remain unchanged through all moments of time. This restrictive condition is frequently violated by the psychological data collected in the real contexts.

Every subject in the researched population must follow the same statistical model (homogeneity of population). This means that the main parameters of the statistical model used to represent data, would remain constant. For example, if a test that measures intelligence with the help of several items, confirms the existence of a singular general factor, than it would imply that the factors and factorial saturations remained constant.

The table 1 summarizes the main aspects that today distinguish the idiographic and nomothetic paradigms. 
Table 1. Main differences between the nomothetic and idiographic approach

\begin{tabular}{|c|c|c|}
\hline & Nomothetic approach & $\begin{array}{l}\text { Idiographic } \\
\text { approach }\end{array}$ \\
\hline Type of anproach & Structural & Processual \\
\hline $\begin{array}{l}\text { Basic unit of } \\
\text { personality }\end{array}$ & The trait/ factor or latent variable & $\begin{array}{l}\text { Dispositional } \\
\text { construct } \\
\text { /behavioral } \\
\text { pattem/ } \\
\text { development path }\end{array}$ \\
\hline $\begin{array}{l}\text { The focus of } \\
\text { investigation }\end{array}$ & $\begin{array}{l}\text { Group level. Personality can be explained } \\
\text { only after the prior determination of } \\
\text { group norms that each individual has to } \\
\text { be reported }\end{array}$ & $\begin{array}{l}\text { Individual level. } \\
\text { Each individual's } \\
\text { personality can be } \\
\text { explained } \\
\text { independently of } \\
\text { any group norm }\end{array}$ \\
\hline $\begin{array}{l}\text { The principle of } \\
\text { measurement }\end{array}$ & $\begin{array}{l}\text { "It is preferably to measure } 1,000 \text { people } \\
\text { in a single occasion" }\end{array}$ & $\begin{array}{l}\text { "It is preferably to } \\
\text { measure one } \\
\text { person in } \\
1,000 \text { occasions" }\end{array}$ \\
\hline $\begin{array}{l}\text { The favorite design } \\
\text { of data collection }\end{array}$ & Transversal (R Technique) & $\begin{array}{l}\text { Longitudinal (P } \\
\text { Technique) }\end{array}$ \\
\hline $\begin{array}{l}\text { Situational } \\
\text { variables }\end{array}$ & Implicitly operationalized or ignored & $\begin{array}{l}\text { Explicitly } \\
\text { operationalized; } \\
\text { the definition is } \\
\text { based on } \\
\text { identifying the } \\
\text { functional } \\
\text { equivalent } \\
\text { attributes }\end{array}$ \\
\hline $\begin{array}{l}\text { The favourite } \\
\text { statistical design }\end{array}$ & $\begin{array}{l}\text { Uses aggregation data to the subjects } \\
\text { (between-subjects design) and situations }\end{array}$ & $\begin{array}{l}\text { Treats each } \\
\text { individual distinct } \\
\text { variations over } \\
\text { different } \\
\text { situations and } \\
\text { occasions of } \\
\text { measurement } \\
\text { (within-subjects } \\
\text { design) }\end{array}$ \\
\hline $\begin{array}{l}\text { The behaviour is } \\
\text { fornalized }\end{array}$ & $\begin{array}{l}\text { Only as latent characteristics } \\
B=f(P)\end{array}$ & $\begin{array}{l}\text { As a conjunction } \\
\text { between } \\
\text { individuals } \\
\text { reactions and } \\
\text { situational } \\
\text { triggers } \mathrm{B}=\mathrm{f}(\mathrm{PxS})\end{array}$ \\
\hline
\end{tabular}




\begin{tabular}{|c|c|c|}
\hline $\begin{array}{l}\text { The description of } \\
\text { personality is } \\
\text { organized in }\end{array}$ & Taxonomy of traits & $\begin{array}{l}\text { Individual } \\
\text { behavioural } \\
\text { patterns }\end{array}$ \\
\hline Explanation & $\begin{array}{l}\text { Captures only the personality's structures } \\
\text { ready-built }\end{array}$ & $\begin{array}{l}\text { Captures both the } \\
\text { structures and } \\
\text { dynamics of } \\
\text { personality }\end{array}$ \\
\hline $\begin{array}{l}\text { The personality } \\
\text { prediction is }\end{array}$ & $\begin{array}{l}\text { Static; predicted score refers to a single } \\
\text { point in time and space where the person } \\
\text { is expected to be. }\end{array}$ & $\begin{array}{l}\text { Dynamic; several } \\
\text { predicted scores } \\
\text { can be calculated } \\
\text { for different } \\
\text { contexts and } \\
\text { occasions the } \\
\text { person will be. }\end{array}$ \\
\hline $\begin{array}{l}\text { Type of } \\
\text { regularities } \\
\text { extracted }\end{array}$ & $\begin{array}{l}\text { General; intend the extrapolation to a } \\
\text { larger population. Risk: general } \\
\text { regularities do not characterize any single } \\
\text { individual. }\end{array}$ & $\begin{array}{l}\text { Local; intend the } \\
\text { explanation and } \\
\text { prediction of a } \\
\text { single individual. } \\
\text { The extrapolation } \\
\text { is restricted only } \\
\text { to typologies } \\
\text { formed by } \\
\text { patterns } \\
\text { communality. }\end{array}$ \\
\hline
\end{tabular}

In the last decade, the international research, passed to increasing the use of idiographic designs that proved to be more adequate in detecting and explanation of individuals regularities. Along with idiographic approaches, multiple repeated measurements were introduced in practice, that many years have been overshadowed by transversal measurements, more convenient but also less sensitive to changes in intra-individual variations.

\section{Structural complex modelling}

Another highlighted trend in psychosocial research is the use of structural modeling complex. A first requirement in the research of a psychological phenomenon is its appropriate operationalization. Operationalization leads to adequate selection of those pertinent variables that give the structure of a phenomenon. But for valid explanations psychosocial phenomena, often requires complex structural tests of variables retained after operationalization. Initially, the modelling of behavioural sciences has been charged for their simplistic and mechanistic nature. The number of the 
manipulated variables was restricted to 2 or 3 at one time and their treatment was carried out successively and not simultaneously.

Because of these limitations in modelling, explanations offered have remained static, not dynamic, and error variance could not be satisfactorily minimized. Unavailability of statistical methods able to reflect the real complexity of relationships between variables that configure this phenomenon, explained the situation. The last decade has produced modelling solutions, which manage to render more appropriately complex psychosocial phenomena in social sciences and particularly in psychology.

\subsection{Structural equation modelling (SEM)}

SEM is one of the latest statistical methodologies that allow a confimatory approach of structural theories about the psychosocial phenomena. There are several aspects for which SEM is far superior to older generation of multivariate procedures.

- SEM is based on a confirmatory analysis, not exploratory, although it can achieve that too.

- The pattern of relationships between variables is specified a priori, so that, it responds perfectly to inferential goals.

- The older generation of multivariate procedures such as explorative factorial analysis, hypothesis testing is almost impossible. Traditional multivariate procedures can not predict and correct errors of measurement, however SEM provides explicit estimators for the errorvariance of these parameters.

- Classical analysis is based only on observed measurements, while SEM analysis can incorporate both observed and latent variables.

- SEM has gained popularity because it can be used for non-experimental researches where other methods are not available to test the theories, or where experimental designs are not feasible. (Bentler, 1980; 2005).

SEM allows controlling for three key issues, not only separately, but especially in concomitance (Arbuckle, 2007). First, SEM allows testing of measurement models, namely the confirmation of relevant theoretical constructs for practice, which, although there are not directly tangible, can be inferred on the basis of relations between indicator variables. Second, SEM allows testing of predictive models in a path analysis form. At this level, SEM can operate simultaneously several exogenous and more endogenous variables linked, which is not possible in classical regressions. The chaining of the endogenous variables allows a very easy testing, but an even more accurate estimation of the moderating and mediating effects, which often are part in the definition of the psychological and social phenomena. Also in the context of SEM path analysis it is possible to test simultaneously two or more regression models. Third, SEM 
can integrate and solve simultaneously the regression models and factor analysis, thus setting up a general model. The traditional multivariate models treat the measurement model separately from data regression model, being unable to integrate and estimate simultaneously the parameters of different variables. Therefore, in the best case, these methods operate sequentially, in steps, the negative effect being to obtain less accurate estimates. The modelling possibilities opened by SEM are more flexible, provided simultaneous estimations being much more accurate compared with classical multivariate modelling of sequential type.

For all these advantages, SEM is currently considered one of the most reliable altematives for modelling multivariate relations that configures complex social science phenomena. SEM has become one dominant trend in all researches aimed to test complex theoretical models, but also in the validation of measurement models.

\subsection{Multilevel modelling}

Social sciences frequently need explanatory models able to take into account the relationship between individual and society or other environmental variables. Most theories about human behaviour accept bilateral interaction between individuals and social contexts. The individual behaviour is influenced by internal factors (traits) but also of social triggers and group characteristics. So, the methodologies used for the analysis of behaviour should take into account this multilevel organization. In the same vein the cognitive psychology shows that recourse to multilevel analysis is required by the organization of the cognitive system itself or the structure of human behaviour. The organization involves four interrelated levels: (a) the level of knowledge; (b) computational level procedural; (c) the representational algorithmic level; (d) the implementation level.

Hierarchical modelling conceptualizes these relations in the form of a hierarchical system in which individuals and groups are defined as different levels in one and the same system. In the multilevel analysis, some data are measured on their natural hierarchical level, while the other variables can be conceptualized at other levels, for example superior levels, using the aggregation of data, or inferior levels, using disaggregation of data. Traditional regression models fail to take into account the multilevel structure of data, leading to lower statistical power. Standard statistical tests are based on the assumption of independence of observations. In the case of data that naturally have a multilevel structure the assumption of independence is violated. So, using conventional statistical methods leads to underestimation of the standard errors, obtaining false significant results (Bryk \& Raudenbush, 1992). The 
multilevel analysis has been advanced as a solution to the common situation in which between individual observations exist dependent relationships (Kreft \& De Leeuw, 1998).

Beyond data analysis that naturally have a hierarchical structure, a more frequent application of multilevel modelling is for longitudinal designs. Longitudinal data or repeated measurements can be regarded as multilevel data, meaning that more measurements are nested for the same individual. In the simplest case of two levels models, the repeated behavioural measurements are considered the lower-level factor, and the individual is conceptualized as a higher level factor.

One advantage of modelling phenomena in a multilevel form of longitudinal data is that data can be collected not only in fixed occasions but also in variable occasions, and also can accommodate a situation where the number of collected data is not the same for each individual (Hox, 2002). A problem for longitudinal measurements is that errors are often correlated, especially when the interval between the measurement occasions is small. The multilevel modelling, in comparison with multiple regressions, provides solutions to these situations that otherwise could lead to erroneous conclusions.

Designing the research in a multilevel fashion became another dominant trend in many longitudinal studies and in those that investigates relations between variables at different hierarchical levels.

\subsection{Neural networks}

Neural networks appeared in neuroscience as ways to implement the Neoconnexionism paradigm (Mc Clelland \&Rumelhart, 1986; 1987), which argues that human cognitive system information is presented, not only by symbols (Classic-symbolic paradigm), but also in the form of values and patterns of activation of elementary units in an artificial neural network (Miclea \& Curşeu, 2003). Haykin (1998) considered that a neural network can be understood as a massively processor, parallel distributed that has a natural tendency to store (in the form of neural weights) the knowledge acquired through a learning process, and make them available for various tasks.

Neural networks are useful not only to simulate the activity of some subsystems of the brain but also, today they represent a growing class of statistical models widely used in predictive and classification tasks. At limit, one can say that linear regression models that acquire the information through the least squares and store them in the regression coefficients are a special case of neural networks. However, traditional regressions are based on a rigid structure of the data model and a set of rigid assumptions regarding the data from which the knowledge is extracted. 
Neural networks have flexible models in comparison with the data structure, their assumptions being more relaxed. They have therefore an increased sensitivity on detecting the presence of an effect (Garson, 1988). Multilayer perceptron (MLP) and Radial basis function (RBF) are types of supervised neural networks, meaning that the results that are predicted using the model can be compared with the known values of a target variable.

In psychology, beyond the modelling of cognitive functions, neural networks have begun to provide interesting results in modelling human behaviour. For example, Mischel and Shoda (1995) in the Cognitive Affective Personality System Theory (CAPS), showed that personality of each individual could be modelled as a predictable set of cross-situational patterns of behavioural that have a relatively invariant underlying organization. The organization and dynamic of behavioural patterns was explained by Mischel and Shoda (1995), using a neural network modelling, as the one shown below.

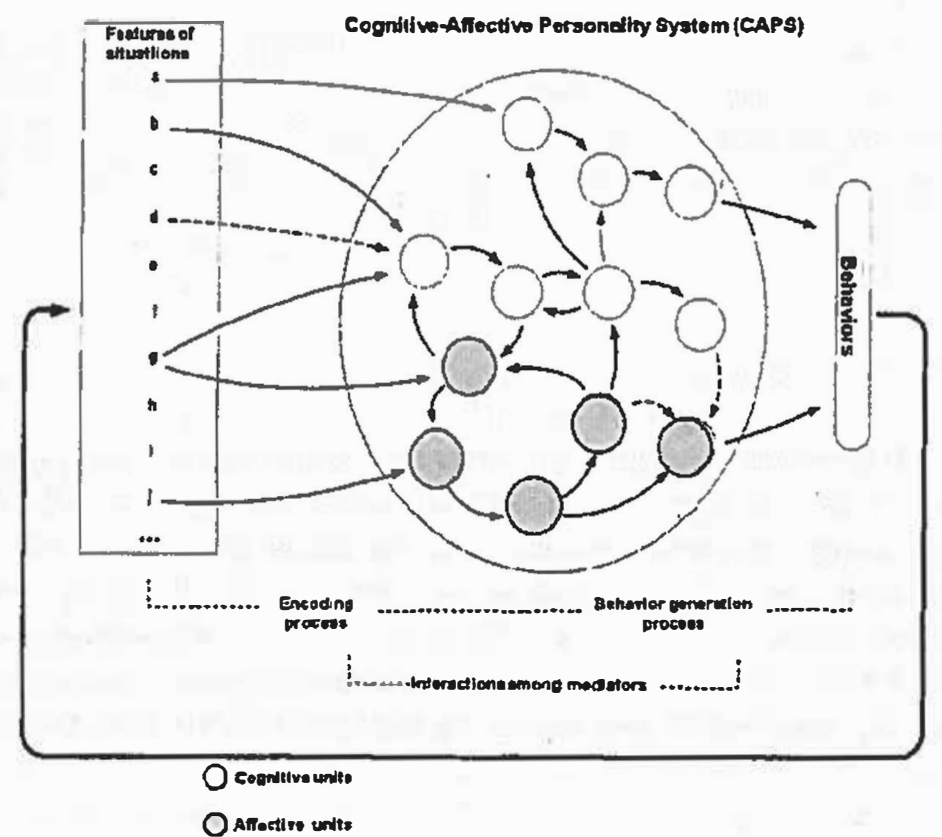

Figure 2. The simplificated ilustration of personality as a cognitive-affective system (source: Mischel and Shoda, 1995)

Using computer simulation, Shoda and Mischel (1998) have built a virtual personality system made up of five detection units, ten processing units and five units of behavioural response. The processing units were fully interconnected, forming a recurrent network, which was exposed to a number of very different conditions. The results confirmed that personality acts as a 
dynamic pattern (of cognitions, emotions and behaviours), which may however be characterized by a form of predictable, non-random variation. Even if thoughts and emotions activated in a person change from one given moment to another, the internal organization of cognitive-affective processing system, as it was recorded by neural networks, remains relatively cross-situational invariant, at least for a short period of time. Thus the neural networks prove that, to the extent that individual perceive a variety of stimuli that are functionally equivalent, he will compress the information processing in a small number of response patterns or attractor-status. Shoda et al. (2002) went further with their research demonstrating that neural networks record a stable pattern of variation of the simulated behaviour of the partners in dyadic relationships.

The modelling of psychosocial phenomenon through neural networks represents another trend of advanced research.

\subsection{The modelling of non-normal distributions}

In the field of social sciences and especially in the field of psychology the studied variables rarely have a normal distribution. All the classical parametrical statistical tests (univariate or multivariate) operate under this very restrictive assumption of the normal distribution. All critical thresholds, depending on which the researcher decides the statistical significance of results, are based on this assumption.

Empirical results often show that this assumption cannot be observed in the collected data. When normal distribution assumption is not met, the classical procedures recommend the use of non-parametric tests for data analysis. Moreover, there are many studies that do not even report the problem of the normality of distribution, which calls into question the validity of results.

The conceptual framework provided by SEM allowed the development of other statistical procedures to compensate the non-normal distributions and to make possible further analysis at a parametric level.

Satorra and Bentler, for example, offered ways of correcting the standard error for the indirect and total effect, the information matrix for maximum likelihood (ML). Other corrections are: the Yuan-Bentler F-test and theYuan-Bentler-Browne statistics based on the analysis of variance and residual covariance; the Yuan-Bentler corrected statistics for non-normal missing data and the Bentler, Berkane and Kano method for heterogeneous kurtosis indices. Thus, in present SEM is more and more preferred as a solution in those researches that operate with non-normal data. 


\section{Objective measurements}

Psychosocial sciences have often been criticized for the subjective nature of data collection instruments. One of the over used instruments in data collection was the questionnaire or self-report method. Beyond the advantages of data collection based on the questionnaire, it is more and more often quoted for the disadvantages of this practice: the inability of quantifying the degree of accuracy in response, the interference of errors caused by involuntary memory errors or by voluntary ones, due to reasons activated in the subject 's response, etc.

At the beginning of this millennium, Bornstein (2001) examined the types of instruments used in psychology for collecting the dependent variables. He revealed that the questionnaire method was used in $65 \%$ of the studies taken in the analysis. In $40 \%$ of these studies the questionnaire was the only method that was used, not being doubled by any other method. Behavioural measurements were used only $27 \%$ of the studies under investigation, and performance measurements in $30 \%$ of the studies. With a much smaller percentage $(9 \%)$ were used interviews, diagnoses and physiological measurements. The cited author considered that if psychologists would continue to increase the frequency usage of the questionnaire as a method of data collection, psychology might become a questionnaire science.

As a result, the academic journals publishers' boards met at some the important international conferences (e.g. ECP 13, ECP 14) declared their negative opinion about the exclusive use of the questionnaire as data collection method, recommending that it should be used only as a secondary, alternative instrument. In the latest years, the suggestions offered by publishers, but especially the advance in technology have led researchers to shift to more objective alternative methods and instruments of data collection.

\subsection{The systematic observation method}

The systematic repeated observation method in several contexts (to increase fidelity) replaces nowadays, more and more frequently, the questionnaire method. Unlike paper records that systematic observations used in the past, today systematic observation is made in two major ways: (1) by audiovideo devices and (2) through computer interfaces. They enable accurate recording of behavioral indicators of interest, eliminating much of the measurement errors.

In many branches of psychology (cognitive psychology, personality psychology, educational psychology, and transportation psychology) computerized administration of stimuli and accurate recording of the way of 
processing-response have become a dominant practice in recent years. This allows both the detection of the current level of development of some characteristics and the determination of their evolution curves.

Such a specialized integrated tool for systematic observations is the Observer XT. It allows the researcher to design a coding scheme for observations, to take samples of behaviour continuously or timely and to analyze the data quantitatively, providing charts and video clips highlights. It enables the researcher to synchronise the behavioural registering with a wide range of data acquisition systems (face emotion detection, eye tracking, physiological measurements).

Systematic observation is frequently coupled with other objective techniques such as biofeedback techniques, electroencephalographic techniques (EEG) or those based on the emission of positrons (PET). Such combinations allow the researcher to capture the interaction of several mental levels and to detect the triggers who maintain certain processing and behavioral responses. Therefore, such measurements allow both theoretical approaches, such as the formulation of explanatory models of behavior, but also more effective practical interventions.

For example, in cognitive-behavioral therapies, video observation and biofeedback allow to identify anxious pattems of behavior (default) and, at the same time, the triggers that maintain these patterns. Many of disharmonic structures of personality are more efficiently restructured today, through the support of objectification and control/self control provided by these techniques. The same form of mixed analysis has been applied successfully in conflicts and negotiations, in couple therapy or in performance training.

\subsection{Field experimental techniques}

In psychology, as well as in other social sciences, the laboratory experiment method remains the most used practice for discovering the causal type relationship. The major advantage that the experiments achieved in laboratory is given by the possibility of establishing a more rigorous experimental control. The control refers to the planning of the designs in such a manner as the unidirectional relationship between the independent variable and the dependent one should not be parasitized by the action of other undesired alternative variables. Besides, the control refers also to the techniques of sampling and equalizing of both the experimental lots and of those of control in pretest phase. Many important authors show that in few situations can absolute control of the parasitized variables be realized (Christensen, 2007; Johnson \& Christensen, 2008). The great disadvantage of the laboratory experiments is given by the low ecological validity. 
A trend that has been set in recent years in social sciences is exactly the revival of the field experiment designs. One of their great aims is the recovery of the ecological validity, ignored for decades in the laboratory experiments. In present four types of experimental and quasiexperimental designs are used outside the laboratory: randomised design, continuous regressive design (in which the treatment is differently applied to the groups formed on either side of a chosen critical point), interrupted series of short time and non-randomised experiments (which use non-equivalent groups of comparison) (Shadish \& Cook, 2009). For these designs have been developed techniques which allow more accurate estimates of the experimental effect even under the social field, conditions in which the control laboratory is not feasible. Among these techniques we can mention: estimation of the effect produced by the treatment in the context of a partly implemented treatment, prevention and analysis of the diminishing of the power of the effect, analysis of the nested type designs, techniques for the regressive discontinuous designs and analysis of propensity scores (Pearl, 2009; Rosenbaum \& Donald, 1983).

\subsection{Functional and imaging investigation methods}

The advance in technology and informatics allowed the construction of new instruments that provides objective measurements and superior methods for data management.

\subsubsection{Electroencephalography and positron emission tomography}

In psychology, behavioural, emotional and cognitive reactions are investigated today by electroencephalography (EEG) frequently coupled with tomography by positron emission (PET). This is because the EEG has a good temporal resolution, but not a spatial one, while PET resolution is superior what concerns the spatial aspect, but not the temporal one. Recent studies investigate issues like: frontal desynchronization as a response to events in the "go/ no-go" tasks Babiloni et al., 2004), quantitative profile of children with ADHD (Monastra et al., 2001), quantitative electroencephalographic profile of children with autism (Chan et al., 2007) etc.

\subsubsection{Functional magnetic resonance (MRI)}

fMRI is another imagistic technique used for the investigation of brain areas involved in different types of tasks, processes and emotions. This technique can not detect the absolute activity of the brain's regions, but only the 
difference of activity in some types of tasks. That is why during the $\mathrm{AMRI}$ investigation a person has to perform some alternative cognitive tasks or is stimulated through triggers which can activate alternative emotions. Each of these conditions is repeated several times, the differences of activation being recorded and codified in computerised data base which facilitates the graphic representation of their statistic processing in order to check different hypotheses.

Today there is a diversity of neuropsychological $\mathrm{AMRI}$ studies which investigate classic or new themes such as: episodic memory and semantics (Mayes et al., 2004), neurological coordinates of attractivity (Anjan et al., 2009), differences of sex in verbal work memory (Goldstein et al., 2005), brain activation in representation of self (Newsome et al., 2010).

\subsubsection{Magnetoencephalography (MEG)}

One of the most advanced forms of non-invasive imagistic investigation is represented by magnetoencephalography (MEG). This combines the advantages of EEG with those of AMRI. The technique is based on the analysis of spatial distribution of the magnetic field, so that one can identify the source of activity which then is superposed over an anatomic area of the brain. The speed of detecting the dynamic modifications in electrical activity is under 10 milliseconds, which overpasses the performances of a AMRI scanning, but in order to create functional maps of the cortical activities, these two techniques are usually used together. Nowadays, MEG is successfully used in order to understand the differentiated functioning of those with Alzheimer, schizophrenia, chronic alcoholism compared with normal people (Georgopoulos et al., 2007; Montez et al.., 2009), in the orientation towards sources (Ahlfors et al., 2010), context encoding in the emotional processing (Barrett et al., 2010), stress and amygdala activation (Hozel et al., 2010), volume of amygdala and the size of socializing network (Bickart et al., 2010), the ability of visualising objects and intelligence (Blazhenkova \& Kozhevnikov, 2010). The use of objective methods for registering cerebral processes coupled with the analyses of coherent patterns of response became a more and more obvious trend in modern research.

\section{Development in qualitative methodology}

Qualitative methodology represents a complementary alternative to the quantitative methodology, the two being sometimes used together. Qualitative data are to be frequently found in social sciences, their gathering and analyzing 
being supported by the development of the afferent qualitative methods and techniques. In this data category are included any of the human communication sub-types (written, audio-visual), behaviours, cultural artefacts, etc.

In the domain of qualitative methodology one can find both formal and informal approaches. The former approach includes: focus-groups, depth interview, content analysis, ethnography and semiotics. In the latter are included applied analyses of unstructured materials such as various reports, feed-back files given by the clients, video clips, audio recordings, etc (Gibbs, 2007).

There are a multitude of goals traced by qualitative research which can be exposed on a continuum from theory to action. Patton (2002) cited the next type of goals: (1) fundamental research which contributes to knowledge and fundamental theory; (2) applied research of social problems; (3) summative evaluation with the purpose of testing programs' efficiency; (4) formative evaluation, with the purpose of improving the programs; (5) action-research, programmed in order to solve specific problems.

\subsection{Paradigms in qualitative methodology}

The evolution of qualitative methods was sinuous, as philosophical and theoretical perspectives on which these are founded are extremely heterogeneous. Lincoln and Guba (2000) identified 5 research paradigms: (1) Positivism; (2) Post-positivism; (3) Critical theory; (4) Constructivism; (5) Participationism. Schwandt (2000) distinguished 3 research perspectives: (1) Interpretivism; (2) Hermeneutics; (3) Social constructivism.

From a diacronichal perspective Denzin and Lincoln (2005) divided the conceptual development of qualitative approaches in six phases.

The first stage is represented by the traditional period appeared between $1900-1945$ under the name of positivism. Qualitative positivism remains even today a strong trend preoccupied by offering reliable and valid interpretations to the investigated phenomena. It has a great similarity with the positivist approach from the quantitative approaches. This is guided either by a deductive scientific either by an inductive action.

In the modernist stage (1945-1970), positivism got even closer to quantitative approaches, specialist giving higher attention to the methodological rigours and procedural formalism in order to be accepted by social sciences.

The "unclear genre" stage (1970-1986) is characterised by the apparition of a great number of alternative approaches, which lead to competition and confusion, reflected in the jargon of qualitative perspectives: Structuralism, Symbolic Interactionism, Phenomenology, Etnomethodology, Micro/Macro Descriptivism, Neomarxism, Post-Structuralism etc.

The representation crises is the next stage in which the focus is on issues concerning power, privileges, race, gender, socio-economical classes, all these contradicting traditional notions such as validity and neutrality. 
The fifth moment refers to a crisis of triple representation, legitimacy and praxis, the interpretative nature of the qualitative writings being rigorously analysed.

Post-experimentalism is the sixth stage in which the borders of the qualitative research are extended in order to include non-fictive creativity, autobiographic ethnography and multimedia representations.

Practitioners of the multiple paradigms that emerge in qualitative approach try to find common ground, and also distinguishing features between their forms of investigation. Initially, it was considered that the positivists and the adherents of new research paradigms will be able to reach a common discourse, but today such a resolution seems unlikely and less useful (Lincoln and Guba, 2000). This happens because post-modemists and post-structuralists assume that there isn't only one truth, but rather that every truth is partial. Identities are more likely fluid rather than fixed which would lead ineluctably to the idea that a single paradigm that brings together all social scientists can not be synthesized.

\subsection{The Specific of Qualitative Paradigms}

Qualitative methodology favours the inductive approach at the expense of the deductive one. The inductive approach is provided a justification for a general explanation, based on the accumulation of a variety of special circumstances, but similar. For example, in Grounded Theory (Glasser and Strauss, 1967; Strauss, 1987), the generation of theories occurs in a reversed form to the classic tradition, which operates with assumptions that are seeking to be demonstrated. More precisely, in the first phase a variety of data are collected, using multiple methods. At their level themes are identified and coded, the codes being grouped in similar concepts. From these concepts categories are formed which form the basis for the developing theory.

The idiographical approach is more preferred than the nomothetical one in all the qualitative researches. The focus of the analysis passes on the highly specific individual factors. Nevertheless, frequently the qualitative research also tries to synthesize the common aspects that appear in multiple individuals who even belong to different groups (for example, common themes in focus groups repeated into different groups).

Finally, qualitative research favours the constructivism at the expense of realism. Realism states that the objects have an independent experience of those who perceive them, the material universe having a single embodiment. Qualitativism followers consider that our descriptions and explanations vary in terms of degree of accuracy, being right only if they meet this material reality. Constructivism assumes that people can't know reality, no matter what that reality might be, but only through constructs and ideas, as such, the access to any form of knowledge is mediated by the pre-existing ground of knowledge, 
the motivational system and competences of the person who realizes knowledge. From a constructivist point of view it is easy to prove that one and the same reality can be perceived and reported in different ways, by distinct people. This statement is more evident in the human universe and the social reality. Constructivist imterpretativism is a paradigm that analyses the significance that people give to their own and others actions. A fundamental assumption of this paradigm is that to understand a phenomenon, this has to be examined not through the decomposition of the variables, but through its integrality. This is opposed to positivism trend, which collects data on parts of the phenomenon, for which qualitativists would endanger the entire. Interpretativism also assumes that there are multiple realities of the phenomena, which differ according to space and time. Within this paradigm the phenomenology and the ethnography are favourite qualitative approaches.

Critical science is another paradigm based on the exploitation of the social world, which it critics, seeking to empower people so that they understand the social functioning and the ways in which unsatisfactory aspects can be changed.

The common feature of these qualitative research paradigms is the exploratory in-depth approach, generating a multitude of descriptive information. Among the collection methods are widely used interactive interviews, written descriptions and observations.

A major difference between a qualitative and a quantitative research is the sampling logic after which it functions. Qualitative research frequently focuses on depth approaches on reduced samples, to a singular case (case study). In quantitative approaches, the logic and the power of random sampling derives from the statistical probability theory. Random samples, statistically representative, have in target the generalization of data and the reduction of errors based on selection. In qualitative research, sampling is done so that the research could be able to access information-rich cases for profound studies. There are many ways of sampling. Significant are the samplings of the extreme cases, of intensity, those of maximization of variance, the ball or chain type, the opportunistic or emerging types, etc. In qualitative studies, there are often used multiple sampling strategies, multiple data types respectively.

The same mixing occurs in the level of methods and data collected under the principle of triangulation of qualitative strategies. Denzin (1978) distinguishes between four types of triangulation in qualitative approaches: (1) Triangulation of data (using a variety of data sources); (2) Triangulation of investigators; (3) Triangulation of theories and perspectives of interpretation; (4) Triangulation of methodologies.

Combining different elements taken from alternative methodologies, the researcher could generate creative strategies. The ideal strategy would require a qualitative three-part approach: (1) Qualitative data; (2) The inductive holistic design of the naturalistic research; (3) The content or case analysis. This strategy is different from that favoured by the hypothetical-deductive 
approaches that include quantitative data, experimental design and statistical analysis.

\subsection{The validity and reliability in qualitative methods}

A perennial problem of qualitative approaches has been represented by the way of treatment of the validity and reliability. These are the criteria that give the rigorousness to a scientific research. Some researchers believe that these criteria are only relevant for the quantitative research, not for the qualitative one (Altheide \& Johnson, 1998; Leininger, 1994), while others try to offer rigor based on similar criteria of fidelity and validity (Lincoln \& Guba, 1985; Rubin \& Rubin, 1995). Guba (1978) discussed the concept of generalization, stating that generalization is a chimera, since it is impossible to generalize in a scientific sense. Generalization is a fragile concept, whose meaning is ambiguous and whose power is variable. So in the case of qualitative researches, Guba and Lincobln (1981) proposed replacing the concept of generalization with the concept of transferability. The accuracy of quantitative approaches could be achieved on the criteria of internal and external validity, reliability and objectivity. In qualitative paradigms these were replaced by specific criteria, Lincoln and Guba (1985) introducing the alternative concepts of: credibility, transferability, dependability and confirmability. In the qualitative methodology, particularly in the constructivist and naturalist current, it was brought into discussion the necessity of substituting the concepts of validity and fidelity. While internal validity explains a fact observed in the terms of an unambiguous relationship between an independent variable and a dependent one, the term of credibility would explain, in addition, what occurs naturally and is observed.

In quantitative methodologies the external validity expresses a relationship observed in a given context, on a certain population, at a given moment, is found in another population located in a different context and time. In other words, external validity refers to the generalization of a relationship from a context of observation to many more, so that the observed relationships become transferable to other populations, too. In qualitative methodologies, constructivism promotes the term transferability as a substitute for the term of generalization. This concept highlights again the fact that the consumer of the research draws his own inferences regarding the contexts and the situations in which certain relationships can be transferred. For constructivism, the replicability, as an essence of the concept of reliability, would be an unrealistic standard for social sciences, as social phenomena and contexts are constantly changing. Therefore, the fixed reference standard in qualitative approaches refers to the contextual dependability of the phenomena. For example, a champion at target shooting and the gun that he uses might be perfectly reliable, 
so that he always hits the aim. However, in rain or wind his target might not be reached, although both the person and the gun retain their features of reliability. The concept of dependability would better describe and compensate those situations where reliability is suspended.

The concept of objectivity in the quantitative methodologies is replaced by the concept of confirmability in the qualitative methodologies, especially in the constructivist current. The first shows the extent to which many people report experiencing the same thing, the subjectivity corresponding to the situation in which a single person is experiencing it. Confirmability is the substitute concept for objectivity and it refers to the degree of conformity of a research consumer of the collected data.

Although constructivists argue that the validity of researches has to suffer because of the strict standards imposed by the quantitative research, a great part of modern qualitative researchers consider that these standards should be maintained to ensure the accuracy of their results. In qualitative research, the researcher is frequently a research tool, too, fact that can affect the reliability of the results. To raise the reliability of the qualitative approaches, several methods were proposed, regarding the fidelity between-evaluators, the variety of observations, test-retest methods and half split methods.

\subsection{Computerized methods of qualitative analysis}

Qualitative analysis of data, especially of the unstructured ones, requires significant time consumption. Therefore there were made computerized programs of qualitative analysis which allows a rapid identification and structuring (on different criteria) of the content themes, so that they can be easily used in different decisions.

The well established software in the field (Atlas.Ti or NVivo) allow a great diversity of inputs (example: text files, image, sound), segmentation, coding schemes (including weighted coding), linking/combining schemes and rapid visualization, including frequency quantifications of different codes that can be further analyzed in quantitative statistical programs.

\section{References}

1. ARBUCKLE, J.L (2007) Amos 16.0 User's Guide, Chicago: SPSS Inc

2. ALTHEIDE, D., JOHNSON, J. M. C. (1998). Criteria for assessing interpretive validity in qualitative research. In N. K. Denzin \& Y. S. Lincoln (Eds.), Collecting and interpreting qualitative materials.(pp. 283-312). Thousand Oaks, CA: Sage. 
3. AHLFORS, S.P., HAN, J., BELliVEAU, J.W., HAMALAINEN, M.S. (2010). Sensitivity of MEG and EEG to source orientation. In Brain Topography, 23(3): 227-232.

4. BABILONI, C., BRANCUCCI, A., ARENDT-NIELSEN, L., BABILONI, F., CAPOTOSTO, P., CARDUCCI, F., CINCOTTI, F., ROMANO, L., CHEN, A C. N., ROSSINI, P. M. (2004) Alpha Event-Related Desynchronization Preceding a Go/No-Go Task: A High-Resolution EEG Study. In Neuropsychology, Vol 18(4), Oct 2004, 719-728.

5. BARRETT, L.F., KENSINGER, E.A. (2010). Context is routinely encoded during emotion perception. Psychol Sci 21(4): 595-599.

6. BENTLER, P.M. (1980). Multivariate analysis with latent variables: Causal modelling. In Annual Review of Psychology, 31, 419-456.

7. BENTLER, P.M. (2005). EQS 6 structural equation program manual. Encino, CA: Multivariate Software.

8. BICKART, K.C, WRIGHT, C.I., DAUTOFF, R.J., DICKERSON, B.C., BARRETT, L.F.. (2010). Amygdala volume and social network size in humans. In Nature neuroscience.

9. BLASTLAND, M., DILNOT, A. (2009). The Numbers Game: The Commonsense Guide to Understanding Numbers in the News, in Politics and in Lije. New York: Penguin Group.

10.BLAZHENKOVA, O., KOZHEVNIKOV, M. (2010). Visual-object ability: a new dimension of non-verbal intelligence. In Cognition. 117(3): 276-301.

11.BORNSTEIN, R. F. (2001). Has psychology become the science of questionnaires? In The General Psychologist, 36, 36-40.

12.BORSBOOM, D. (2006). The attack of the psychometricians.

Psychometrika, 71, 425-440.

13.BRYK, A., RAUDENBUSH, S. W. (1992). Hierarchical Linear Models for Social and Behavioral Research: Applications and Data Analysis Methods. Newbury Park, CA: Sage.

14.BYRNE, B (2006) Structural Equating modeling with AMOS, London, LEA Publishers

15.CAPALDI E. J., PROCTOR R.W. (2008) Current and Future Trends in Experimental Psychology (pp. 24-38). In S.F. Davis (Ed) Handbook of Research Methods in Experimental Psychology, Blackwell Publishing

16.CHAN, A.S.; SZE, S.L.; CHEUNG, M. (2007) Quantitative electroencephalographic profiles for children with autistic spectrum disorder. In Neuropsychology, Vol 21(1), Jan 2007, 74-81

17.CHATTERJEE, A., THOMAS, A., SMITH, S.E., AGUIRRE, G.K. The neural response to facial attractiveness. In Neuropsychology, Vol 23(2), Mar 2009, 135-143.

18.CHRISTENSEN, L. (2007). Experimental Methodology (10th Ed.). Boston: Allyn \& Bacon.

19.DENZIN, N. K. (1978) The research act, NY: McGraw-Hill 
20.DENZIN, N. K., LINCOLN, Y. S. (1998). Collecting and interpreting qualitative material. Thousand Oaks, CA: Sage.

21.DENZIN, N. K., LINCOLN, Y. S. (2005). Paradigms and perspectives in contention. In N. K. Denzin si Y. S. Lincoln (Eds.), Handbook of qualitative research (3rd ed., pp. 183-190).Thousand Oaks, CA: Sage.

22.EPSTEIN, S., O.BRIEN, E.J. (1985). The person-situation debate in historical and current perspective. In Psychological Bulletin, 98, 513-537.

23.GARSON, D.G. (1998). Neural networks: An introductory guide for social scientist. London: Sage

24.Georgopoulos AP et alii. (2007). Synchronous neural interactions assessed by magnetoencephalography: a functional biomarker for brain disorders. In $J$ Neural Eng 4 (4): 349-55.

25.GIBBS, R.G. (2007) Analyzing qualitative data, London, Sage

26.GLASER, B. G., STRAUSS, A. (1967). The discovery of grounded theory: Strategies for qualitative research. Chicago: Aldine.

27.Goldstein, J. M. Et alii. Sex differences in prefrontal cortical brain activity during fMRI of auditory verbal working memory. In Neuropsychology, Vol 19(4), Jul 2005, 509-519.

28.GUBA, E. G., LINCOLN, Y. S. (1981). Effective evaluation. San Francisco: Jossey-Bass.

29.GUBA, E. G., LINCOLN, Y. S. (1989). Fourth generation evaluation. Newbury Park, CA: Sage.

30.Hölzel, B.K. et alii. (2010). Stress reduction correlates with structural changes in the amygdala. In Soc Cogn Affect Neurosci 5(1): 11-17

31.HAYKIN (1998) Neural networks: A comprehensive foundation, PrenticeHall.

32.HOX, J. (2002) Multilevel analysis: tehniques and applications, London: LE 33.JOHNSON, J.A. (1997). Units of analysis for the description and explanation of personality. In Hogan,R., Johnson, J.A. si Briggs, S.R. (eds.), Handbook of personality, 73-93. San Diego: Academic.

34.JOHNSON, B., CHRISTENSEN, L. (2008). Educational Research Methods. London: SAGE

35. KREFT, I., DE LEEUW, J. (1998). Introducing Multilevel Modeling. Sage 36.LEININGER, M. (1994). Evaluation criteria and critique of qualitative research studies. In J. M. Morse (Ed.), Critical Issues in Qualitative Research Methods. Newbury Park, CA: Sage.

37.LINCOLN, Y. S., GUBA, E. G. (1985). Naturalistic inquiry. Beverly Hills, CA: Sage.

38.LINCOLN Y.S., GUBA, E. (2000). Paradigmatic controversies, contradictions and emerging confluencis. pp 163-188. In N.K. Denzin si Y.S. Lincoln (Eds), Handbook of qualitative research, Thousan Oaks CA: Sage 39.MAYES, A R., MONTALDI, D., SPENCER, TJ., ROBERTS, N (2004) Recalling Spatial Information as a Component of Recently and Remotely 
Acquired Episodic or Semantic Memories: An JMRI Study. Neuropsychology, Vol 18(3), 426-441.

40.MCCLELLAND, J.L., RUMELHART, D.E. AND THE PDP RESEARCH GROUP. (1986). Parallel distributed processing: Explorations in the microstructure of cognition, vol. II. Cambridge, MA: MIT Press.

41.MCCRAE, R.R., COSTA, P.T., JR. (1999). A Five-Factor Theory of personality. In L.A. Pervin si O.P. John (eds.), Handbook of personality: Theory and research, 2nd ed., 139-153. New York: Guilford.

42.MCCRAE, R.R. (2005). Personality structure. In V.J. Derlega, B.A. Winstead si W.H. Jones (eds.), Personality: Contemporary theory and research, 3rd. ed., 192-216. Belmont, CA: Wadsworth Group.

43.MERVIELDE, I. (1994).Trait theory: back to the future. In Psychological inquiny, 5, 153-156.

44.MICLEA, M., CURSEU, P. (2003). Modele neurocognitive. Cluj-Napoca: ASCR.

45.MISCHEL, W., SHODA, Y. (1995). A cognitive-affective system theory of personality: Reconceptualizing situations, dispositions, dynamics, and invariance in personality structure. In Psychological Review, 102, 246-268. 46.MOLENAAR, P.C.M. (2004). A manifesto on psychology as idiographic science: Bringing the person back into scientific psychology, this time forever. Measurement, 2, 204-218.

47.MONASTRA, V. J., LUBAR, J. F., LINDEN, M. (2001). The development of a quantitative electroencephalographic scanning process for attention deficit-hyperactivity disorder: Reliability and validity studies. In Neuropsychology, Vol 15(1), Jan 2001, 136-144.

48.MONTEZ, T. ET ALII (2009). Altered temporal correlations in parietal alpha and prefrontal theta oscillations in early-stage Alzheimer disease. PNAS 106 (5): 1614-1619.

49.NEWSOME, M R. ET ALII (2010) Brain activation while thinking about the self from another person's perspective after traumatic brain injury in adolescents. In Neuropsychology, Vol 24(2), 139-147.

50.PATTON, M.Q. (2002). Qualitative research and evaluation methods, London, Sage

51.PEARL, J. (2009). Causality: Models, Reasoning, and Inference. Cambridge University Press, Second Edition.

52.ROSENBAUM, P. R., RUBIN, D. B. (1983). The central role of the propensity score in observational studies for causal effects. In Biometrika 70 (1): 41-55

53.RUBIN, H. J., RUBIN, I. S. (1995). Qualitative interviewing: The art of hearing data. Thousand Oaks, CA: Sage.

54.SCHWANDT, T.A. (2000). The epistemological stances fosr qualitative inquiny: interpretivism, hermeneutics and social constructivism pp.189-214. In 
N.K. Denzin si Y.S. Lincoln (Eds), Handbook of qualitative research, Thousan Oaks CA: Sage

55.SCHWANDT, T. A. (2007). The Sage dictionary of qualitative inquiry (3rd ed.). Thousand Oaks, CA: Sage.

56. SCHMITZ, B. (2000). Auf der Suche nach dem Verlorenen Individuum: Vier Theoremr zur Agregation von Prozessen. Psychologische Rundschau, 51, 83-92.

57.SHODA, Y., MISCHEL, W. (1998). Personality as a stable cognitiveaffective activation network: Characteristic patterns of behavior variation emerge from a stable personality structure. In S.J. Read si L.C. Miller (eds.), Connectionist and PDP Models of Social Reasoning and Social Behavior, 175208. NJ: Lawrence Erlbaum.

58.SHODA, Y., LEETIERNAN, S. (2002). What remains invariant?: Finding order within a person's thoughts, feelings, and behaviors across situations. In D. Cervone \& W. Mischel (Eds.), Advances in personality science (pp. 241270). New York: Guilford Press.

59.SHODA, Y., LEE TIERNAN, S., MISCHEL, W. (2002). Personality as a dynamical system: Emergency of stability and distinctiveness from intra- and interpersonal interactions. In Personality and Social Psychology Review, 6, 316-325.

60.STRAUSS, A. (1987). Qualitative analysis for social scientists. Cambridge, England: Cambridge University Press.

61.TEN BERGE, M.A., DE RAAD, B. (1999). Taxonomies of Situation from a Trait Psychological. Thousand Oaks, CA: Sage.

62. WILLIAM R. S., THOMAS, D. C. (2009) The Renaissance of Field Experimentation in Evaluating Interventions. In Annual Review of Psychology, 60: 607-629 